Article

\title{
Energy Demand in the State of Kuwait During the Covid-19 Pandemic: Technical, Economic, and Environmental Perspectives
}

\author{
Hamad M. Alhajeri ${ }^{1, *}$, Abdulrahman Almutairi ${ }^{1}$, Abdulrahman Alenezi ${ }^{1}$ \\ and Faisal Alshammari ${ }^{2}$ \\ 1 Mechanical Power and Refrigeration Department, College of Technological Studies, PAAET, \\ Shuwaikh 700030, Kuwait; asa.almutairi@paaet.edu.kw (A.A.); Ah.alenezi@paaet.edu.kw (A.A.) \\ 2 Engineering and Environmental Department, Ministry of Electricity and Water, Ministries Zone 12010, \\ Kuwait; fmnalshammari@mew.gov.kw \\ * Correspondence: hm.alhajeri@paaet.edu.kw
}

Received: 14 July 2020; Accepted: 21 August 2020; Published: 24 August 2020

\begin{abstract}
The present paper reports the impact of the Covid-19 pandemic on the electricity peak load and power generation in the State of Kuwait during the partial and full curfews imposed in March, April and May 2020 using historic data measured data and the predictions provided by a statistical genetic algorithm model. A quantitative assessment is made of the economic and environmental impacts caused by partial and full lockdowns. Comparison of measured peak demand for 2019 and 2020 with predicted peak demand for 2020 has: (i) enabled an accurate evaluation of residential energy consumption in the state of Kuwait at nearly 18 MWh yearly the highest energy consumption per capita in the world, (ii) shown that the imposition of the curfews to reduce the spread of COVID-19 caused a fall in the demand for electrical power of $17.6 \%$ compared with the expected demand and (iii) quantified the reduction in $\mathrm{CO}_{2}, \mathrm{NO}_{\mathrm{x}}$ and $\mathrm{CO}$ pollutant emissions produced by power plants due to less fuel being consumed. A mathematical model has been developed to predict the peak electric load in the national grid according to climatic data supplied by the Meteorological Department of Civil Aviation of Kuwait and National Control Center (NCC).
\end{abstract}

Keywords: COVID-19; energy forecasting; curfew; energy demand; peak load

\section{Introduction}

COVID-19 has had a seriously adverse effect on the global economy and posed a decisive challenge to healthcare systems worldwide [1]. The World Health Organization declared that the COVID-19 constituted a high-risk globally [2]. As the virus spread internationally, most countries took strict actions to mitigate the outbreak through early detection, social isolation, a ban on congregations and imposition of quarantines. Countries across the world varied in the degree to which they promoted social distancing, some setting a full lockdown, others using either a partial curfew or requesting their citizens to stay at home. The preventive actions led to an immediate impact that changed lifestyles and energy consumption patterns. COVID-19 has profoundly impacted all sectors of the world economy. One severely affected industry is energy, which led to a flooding of the market with large quantities of crude oil, due to supply being much higher than demand. With a steep decline in energy consumption due to reduced transport, trade and global demand for electricity as a result of protection measures. The International Air Transportation Association (IATA) estimates the air travel industry alone faces a loss of US $\$ 113$ billion revenue [3]. The decrease in global electricity demand during the period of lockdowns has been confirmed by several sources, such as the International Energy Agency (IEA), which has evaluated the impact of the COVID-19 crisis on energy demand [4]. However, the reduction 
in electricity consumption has reduced environmental impact through lowering greenhouse gas and pollutant emissions which is considered a positive aspect of the COVID-19 pandemic. The impact of COVID-19 on demand needs to be assessed and a model produced to enable likely demands to be accurately forecast.

Daily electricity demand forecasting has been investigated by numerous researchers using several methods. The accuracy of the methods used in predicting electricity load depends mainly on the available data, the geographical region studied and the forecasted time period [5]. Leme et al. presented a comparative study between three approaches: random forest, gradient boosting and support vector regression [6]. The study's dataset was obtained from the Brazilian Interconnected Power Grid and was used in forecasting short- and long-term energy load. The gradient boosting method was found to produce the best results, with a mean absolute error of $13 \%$ using variables such as the weekly energy load, maximum demand, day of the week, generated energy, hydroelectric generation and average temperature, and artificially created variables, such as energy load log-return.

Sigauke and Chikobvu conducted a comparative analysis using three models based on a seasonal auto-regressive integrated moving average to forecast the daily peak demand in South Africa [7]. Their model used only the variables of electricity load demand, day of the week, holidays and seasonality. Their numerical results, evaluated using absolute mean error, indicated that the forecast accuracy varied based on the models and input variables used. Another widely used method for forecasting short- and long-term electricity consumption is the genetic algorithm. Elias et al. conducted an hourly load forecasting study via a backpropagating genetic algorithm of an unnamed city in Great Britain [8] using two meteorological variables (wet and dry bulb temperatures), time period (hour of the day, day of the week and holidays) and previous average and hourly loads. The results showed excellent agreement, with a mean absolute percentage error of $3.81 \%$ for hourly prediction. The authors concluded that there were two ways to improve this method: (1) increase the number in the initial generation, and (2) increase the size of the chromosomes. For the state of Kuwait, the prediction of its annual energy consumption using social indicators has been studied by [9]. Four social indicators were used: gross domestic product, population, imports and exports. The results showed that the genetic algorithm model used was able to accurately predict the annual energy consumption.

One of the major impacts of COVID-19 in the power generation sector is a substantial reduction in polluting emissions produced due to lower electricity consumption [10-13]. Azzam and Dincer investigated the impact of COVID-19 on the energy sector for the month of April in the province of Ontario in Canada [14]. They carried out an hourly comparison of the energy demand during April 2019 and April 2020. The Canadian government announced the closure of all non-essential businesses on March 25. The results showed a 14\% reduction in the monthly electricity demand, with the highest daily reduction of $25 \%$, which is equivalent to a 400,000 tonne reduction in $\mathrm{CO}_{2}$ emissions and a savings of US\$131,844.

Gillingham et al. investigated the short- and long-term effects on energy consumption of the COVID-19 pandemic [15]. Polynomial regression and a two-step augmented regression prediction model were used for forecasting energy demand during the test period. The confidence interval of the prediction was used to check the accuracy of the model rather than the error metric. The study found a $20 \%$ decline in gas-fired electricity and an approximate $5 \%$ decline in coal-fired electricity. Comparatively, the overall reduction in electricity demand was around $7 \%$ for the period of late March to June 7, 2020. Other studies have also discussed the effect of lockdowns on energy consumption; Aruga et al. examined how the easing of lockdown measures influenced energy consumption in India [16]. Their results showed that energy consumption increased with the number of cases of COVID-19. Furthermore, as lockdowns eased, energy consumption started to recover even with increases in COVID-19 cases.

The above studies highlight the need for load and energy forecasting to enable electricity utilities to manage their resources effectively and ensure a secure electricity supply to the end-user during such 
emergencies as the COVID-19 pandemic. However, the above studies lacked data on and an analysis of the effects of full lockdown and partial curfew on energy consumption.

The general and specific research gaps in this field include the following:

- The impact of a pandemic outbreak on the electricity sector using recorded and forecasted data.

- The economic and environmental impacts of changes in forecasted power generation load that result from a pandemic outbreak.

- The assessment of the effect of a full lockdown and/or partial curfew on energy consumption and peak load for a national grid.

- Lack of authenticated information available in the literature or government sources on residential electricity consumption in Kuwait.

The present work introduces actual information and analysis of the impact of the COVID-19 pandemic and its effect on the electricity sector using data from the Kuwait electrical national grid.

\section{Study Method}

\subsection{Regression Model}

Regression analysis is widely used in science applications, statistically modelling the relation between variables. The technique has shown proven capability to deliver useful and accurate statistical analyses [17]. The technique is used here to evaluate energy demand where a number of factors affect the outcome. Simple regression models can be described as the linear sum, or combination, of a set of equations of the form:

$$
Y=\sum_{i}^{n} c_{i} \beta_{i}(X)+\epsilon(1)
$$

where $Y$ is the dependent variable, $\beta_{i}(X)$ represents the basic function of the independent variable vector $X, c_{i}$ are coefficients, $\epsilon$ is the error term and $i=1,2, \ldots, n$. The dependent variables represent either the peak load or the total power generation, whereas the value of coefficients and the error term need to be evaluated from the regression model based on historical data. The independent variable, vector $X$, includes weather conditions and some dummy variables, as elaborated in the next section.

\subsection{Genetic Algorithms}

Extracting useful information from large data sets has been a long-time problem for scientists. However, the development of evolutionary algorithms has enabled scientists and engineers to solve major real-world problems. Genetic algorithms (GA) are tools widely used in many applications, such as business, science and engineering, usually for optimization purposes and forecasting. The GA is a form of stochastic optimization, inspired by the principles of natural evolution, and consists of five parts: initial population, the fitness function, selection procedure, crossover, and mutation. Through the selection process, those members that meets the fitness criteria have a better chance of mating and reproducing their features in the following generation. Next is the crossover process in which the parents are selected, and the offspring are generated. Through the mutation phase, the chromosome of the produced offspring goes through finetuning whilst preserving the necessary genetic information. This iterative process is repeated until the fitness criteria are met.

The GA is often used to estimate model parameters [18]. Figure 1 shows the operating principle for the forecasting models developed using Matlab and Simulink. The equation can contain any mathematical function: basic algebraic, trigonometric, exponentiation, squashing, logical, etc. Detailed information of the genetic algorithm technique is readily available in the literature [19-21]. The task is to obtain the best data fitting linear/nonlinear functional form. 


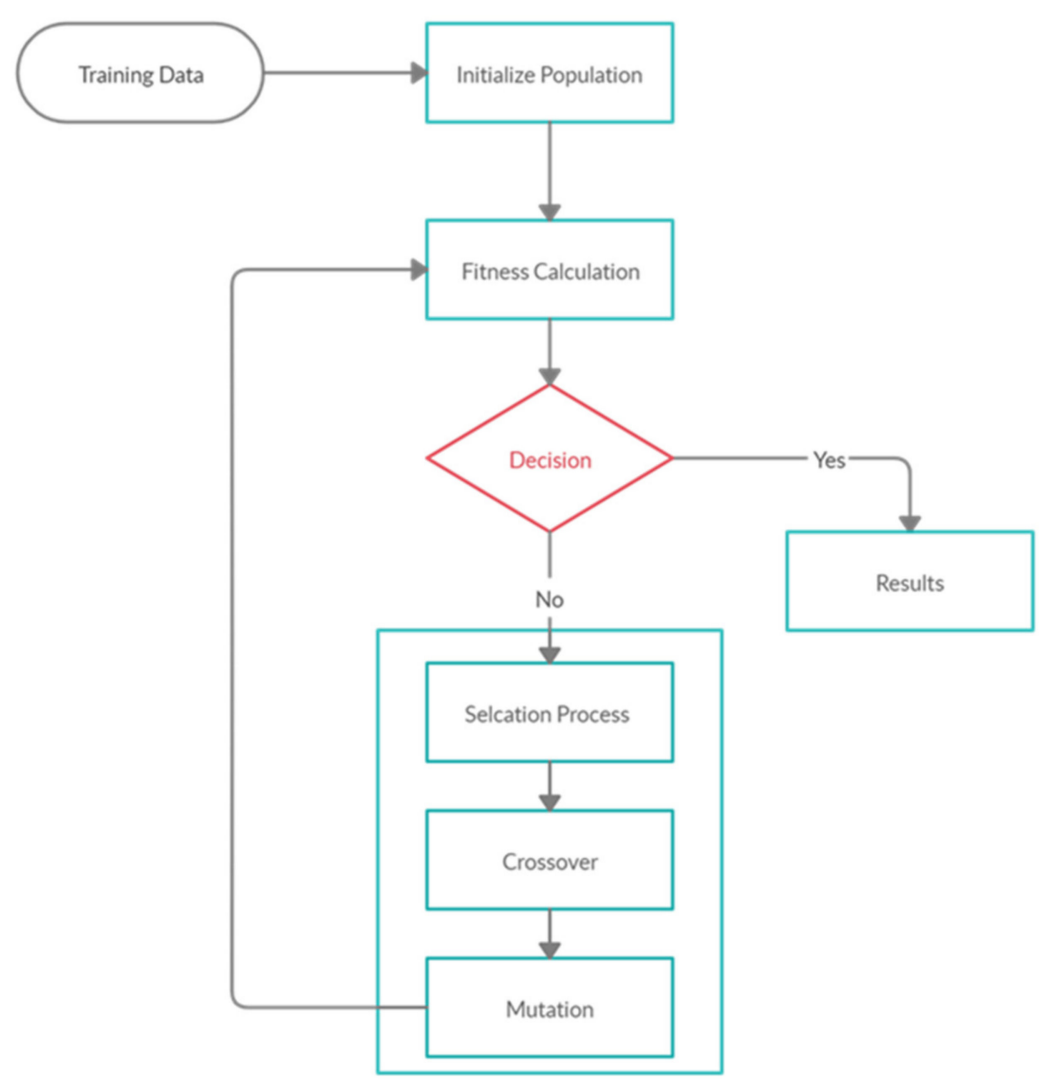

Figure 1. Block diagram of the proposed model based on genetic algorithm.

The model contains multiple independent variables that influence peak electricity demand, $Y$ : Maximum temperature, $T_{\max } ;$ Temperature of previous day, $T_{\max , B} ;$ Humidity, $\mathrm{H}$; Minimum temperature, $T_{\min }$; Weekends and holiday periods, $\mathrm{WH}$; and whether Ramadan is included, $R M$. The mathematical model takes the following basic form:

$$
Y=F\left(T_{\operatorname{Max}}, T_{\max , B}, H, T_{\min }, W H, R M\right)
$$

The model for the peak load is:

$$
\begin{gathered}
Y=4318+2204 \times W H+19.6 \times T_{\max }+472.2^{R M}+2.1 \times T_{\max } \times T_{\min }+2 \times T_{\max } \times T_{\max , B} \\
+\operatorname{Tan}\left(2.1 \times T_{\max } \times T_{\min }\right)-74.3 \times T_{\max , B} \times W H
\end{gathered}
$$

Developing the model is an iterative procedure. The model needs to go through adequacy checks to determine its fitting quality. The model quality can be evaluated using three performance indicators, mean absolute error, MAE (Equation (4)), root-mean-squared error, RMSE (Equation (5)) and determination coefficient, $R^{2}$ (Equation (6)). The iterative procedure works to minimize the difference between the data set and the predicted data in each step. These indicators are expressed, respectively, in standard form as follows:

$$
\begin{aligned}
M A E & =\frac{1}{n} \sum_{i=1}^{n}\left|y_{i}-\hat{y}_{i}\right| \\
R M S E & =\sqrt{\frac{1}{n} \sum_{i=1}^{n}\left(y_{i}-\hat{y}_{i}\right)^{2}}
\end{aligned}
$$




$$
R^{2}=1-\frac{\sum_{i}\left(y_{i-} \hat{y}_{i}\right)^{2}}{\sum_{i}\left(y_{i}-\bar{y}_{i}\right)^{2}}
$$

\subsection{Economic and Environmental Analysis}

The economic impact of the pandemic has been evaluated using actual figures recorded by the Ministry of Electricity and Water (MEW) based on invoices issued by the Kuwait Petroleum Corporation (KPC). The cost of energy consumed depends on the type of fuel, where the produced power is highly dependent on the capacity and efficiency of the power unit and which technologies are used. In the state of Kuwait, steam power plants represent $47.7 \%$ of total installed capacity while combined cycle power plants account for $38.2 \%$, gas turbine engines $13.7 \%$ and renewable power plants $0.4 \%$ [22]. The economic impact is evaluated by assessing the actual fuel consumption in 2020 under pandemic conditions with fuel consumed during 2019 and the forecast values for 2020 based on normal circumstances.

In the present work, the undesired products released during power generation such as $\mathrm{CO}_{2}, \mathrm{NO}_{\mathrm{x}}$ and $\mathrm{CO}$ will be evaluated using specialized software and validated by the following empirical expressions:

$$
\begin{gathered}
m_{C O}=\frac{0.179 \times e^{\left[7800 / T_{a d}\right]}}{P_{e}^{2} \tau_{x}\left(\Delta P_{e} / P_{e}\right)^{0.5}} \\
m_{N O_{x}}=\frac{0.15 \times 10^{16} \tau_{x}^{0.5} e^{\left[-71100 / T_{a d}\right]}}{P_{e}^{0.05}\left(\Delta P_{e} / P_{e}\right)^{0.5}}
\end{gathered}
$$

where the $m_{C O}$ and $m_{N O_{x}}$ denote emissions (in grams per kilogram of fuel) for carbon monoxide and nitrogen oxide, respectively. The terms $\tau_{x}$, and $\Delta P_{e} / P_{e}$ represent residence time and non-dimensional pressure drop across the combustor, while $T_{a d}$ refer to the adiabatic flame temperature in the combustion chamber. These empirical expressions are used only to evaluate the emissions in the gas turbine combustion chamber. Reference [23] has further information about the empirical equations of gas turbines engine emissions.

\subsection{Period of Study and Assumptions Made}

The current study was conducted for three consecutive months starting in March and ending in May 2020. This period was selected carefully to cover four different situations affected the performance of the national electrical grid. Also investigated was the pattern of electrical supply to demonstrate the impact of the Covid-19 pandemic on both peak and total energy consumption. It is well-known that the Kuwaiti government promoted social distancing in three stages starting with asking the residents to stay at home then imposing a partial, and finally imposing a full curfew, as illustrated in Table 1.

Table 1. Four different conditions over the test period.

\begin{tabular}{cccc}
\hline No. & Description & From & To \\
\hline 1 & Normal Condition & 1-March-2020 & 12-March-2020 \\
2 & Stay at Home Request & 13-March-2020 & 21-March-2020 \\
3 & Partial Curfew & 22-March-2020 & 10-May-2020 \\
4 & Full Curfew & 11-May-2020 & 30-May-2020 \\
\hline
\end{tabular}

In the literature, mathematical and statistical modelling is widely used in many scientific applications, and simplifying assumptions are made based on the nature of the study, computational software capability and availability of data. To reduce the complexity of the problem, the model is simplified as much as possible while retaining its ability to accurately imitate reality. In the current study, the analysis was conducted based on the following assumptions: 
- The load reduction was attributed to the use of gas turbine engines because these possess the highest heat rate of all the technologies used in the Kuwait power network. The performance data and the models of the selected gas turbine engines are shown in Table 2.

- The gas turbine engines configuration and loads are designated based on the peak reduction.

- The supplied fuel was natural gas, and its composition is shown in Table 3.

- The combustion process was completed in the combustor with $2 \%$ heat loss and nitrogen was treated as an inert gas.

Table 2. The selected gas turbine engines from Kuwait power system.

\begin{tabular}{ccc}
\hline Description & GE-LM6000 & GE-9FA \\
\hline Power output $(\mathrm{MW})$ & 45.00 & 265.00 \\
Thermal efficiency $(\%)$ & 39.40 & 37.80 \\
Heat rate $(\mathrm{kJ} / \mathrm{kWh})$ & 9127 & 9028 \\
Pressure ratio & 29.10 & 16.80 \\
Exhaust Mass flow $(\mathrm{kg} / \mathrm{s})$ & 130.0 & 640.00 \\
Exhaust Temperature $\left({ }^{\circ} \mathrm{C}\right)$ & 700.0 & 870.0 \\
Ramp rate $($ MW/minute) & 50.00 & 22.00 \\
\hline
\end{tabular}

Table 3. Natural gas composition based on molar fraction.

\begin{tabular}{cc}
\hline Component & Molar Fraction (\%) \\
\hline Methane $\left(\mathrm{CH}_{4}\right)$ & 93.35 \\
Ethane $\left(\mathrm{C}_{2} \mathrm{H}_{6}\right)$ & 0.201 \\
Propane $\left(\mathrm{C}_{3} \mathrm{H}_{8}\right)$ & 0.028 \\
Nitrogen $\left(\mathrm{N}_{2}\right)$ & 6.421 \\
\hline
\end{tabular}

\subsection{Data Set}

The data for the regression analysis were collected from the MEW through the National Control Center (NCC) in Kuwait because the NCC oversees monitoring and managing of all electricity in Kuwait. The data set was gathered for a period of 5 years for all residential, commercial and industrial sectors, including daily, maximum and minimum electricity loads. Furthermore, to guarantee accurate weather readings all weather data recorded by the Meteorological Department of Civil Aviation at Kuwait National Airport was checked with the NCC, which is geographically located in the center of the country. The collected weather data consisted of daily, maximum and minimum temperatures and relative humidity on an hourly basis with the recorded peak electrical load. The climatic data and recorded daily peak electrical load for the previous three years are shown in Figure 2. The data sets show that the electricity load depends on several variables, and its sensitivity to each variable is different. The electricity consumption is considered most sensitive to the maximum daily temperature. The temperature regularly reaches over $50^{\circ} \mathrm{C}$ and the rise in electricity consumption during the summer period is attributed to the substantial cooling demand. Other meteorological variables significantly influence electricity consumption, e.g., relative humidity, minimum temperature and the maximum temperature of the previous day.

Additionally, from the data sets, we see changes in electricity consumption due to non-meteorology variables, such as variations in human behavior, e.g., at weekends and national holidays. The practice of fasting during the holy month of Ramadan also has a significant effect since working time in the government sector is reduced by approximately two hours daily, while in contrast, the commercial business sector extends working hours to midnight. 


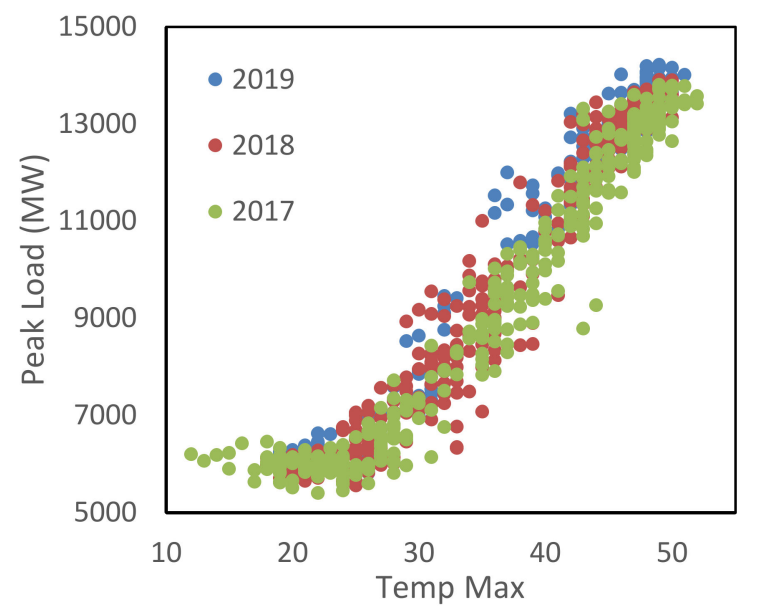

(a)

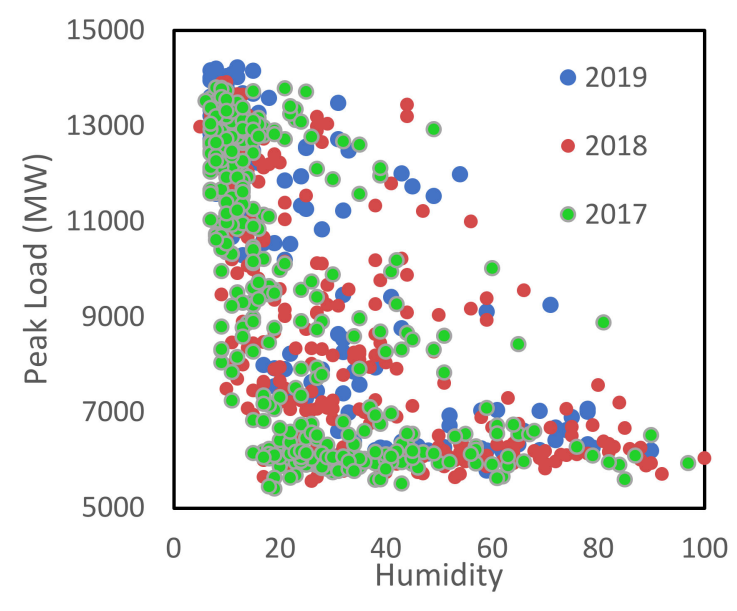

(b)

Figure 2. Dataset of the peak electrical load vs (a) daily maximum temperature, and (b) relative humidity $\%$.

\section{Results and Discussion}

This section presents the model, its evaluation, and the results of estimated peak load, energy consumption, economic savings and environmental impact during the COVID-19 pandemic in the state of Kuwait. For the four periods selected to illustrate the influence of the pandemic on the performance of the national electrical grid the actual data were compared with the predicted demand for the year 2020, as well as actual demand for the year 2019, to illustrate the outcomes for different baselines. The electricity consumption of the residential segment was evaluated accurately by taking advantage of the lockdown to help the MEW to identify, address and mitigate likely future growth in demand. The error percentages of the developed model are presented graphically to demonstrate its applicability to the study objectives.

\subsection{Model Evaluation}

The regression model obtained for the peak load was validated with actual data and found to be accurate. The proposed models were validated on a daily basis comparison for the three target months. As an example, the month of April was chosen to show a daily comparison between the predicted value of the regression analysis and the actual value for the years from 2016 to 2019, see Figure 3. The model predicted values shown adequate accuracy in predicting peak load with maximum deviation in April 2019 of 10\%. The model's average absolute error for the four consecutive years is $2.7 \%$.

Figure 4a compares the predicted daily peak load with the actual peak load for three consecutive years for the three months: March, April and May. The calculated predicted peak load average absolute error is $2.3 \%$ with a maximum difference of $11 \%$. The deviation between the expected peak load of the regression analysis and the actual peak load was mainly due to the firing of a local processing plant which immediately increased the peak load by $100 \mathrm{MW}$, causing the average absolute error to increase by $1.2 \%$. Other factors affect the accuracy of the model, such as temperature change throughout the day and dusty weather. Kuwait is known for its dusty weather and the average number of dust storms in April and May occupy 3.5 days a month [24]. Figure $4 \mathrm{~b}$ represents the difference between the predicted daily total generation $(\mathrm{MWh})$ and the actual daily total generation. The result shows a maximum deviation of $10 \%$ and average absolute error of $2.3 \%$. 


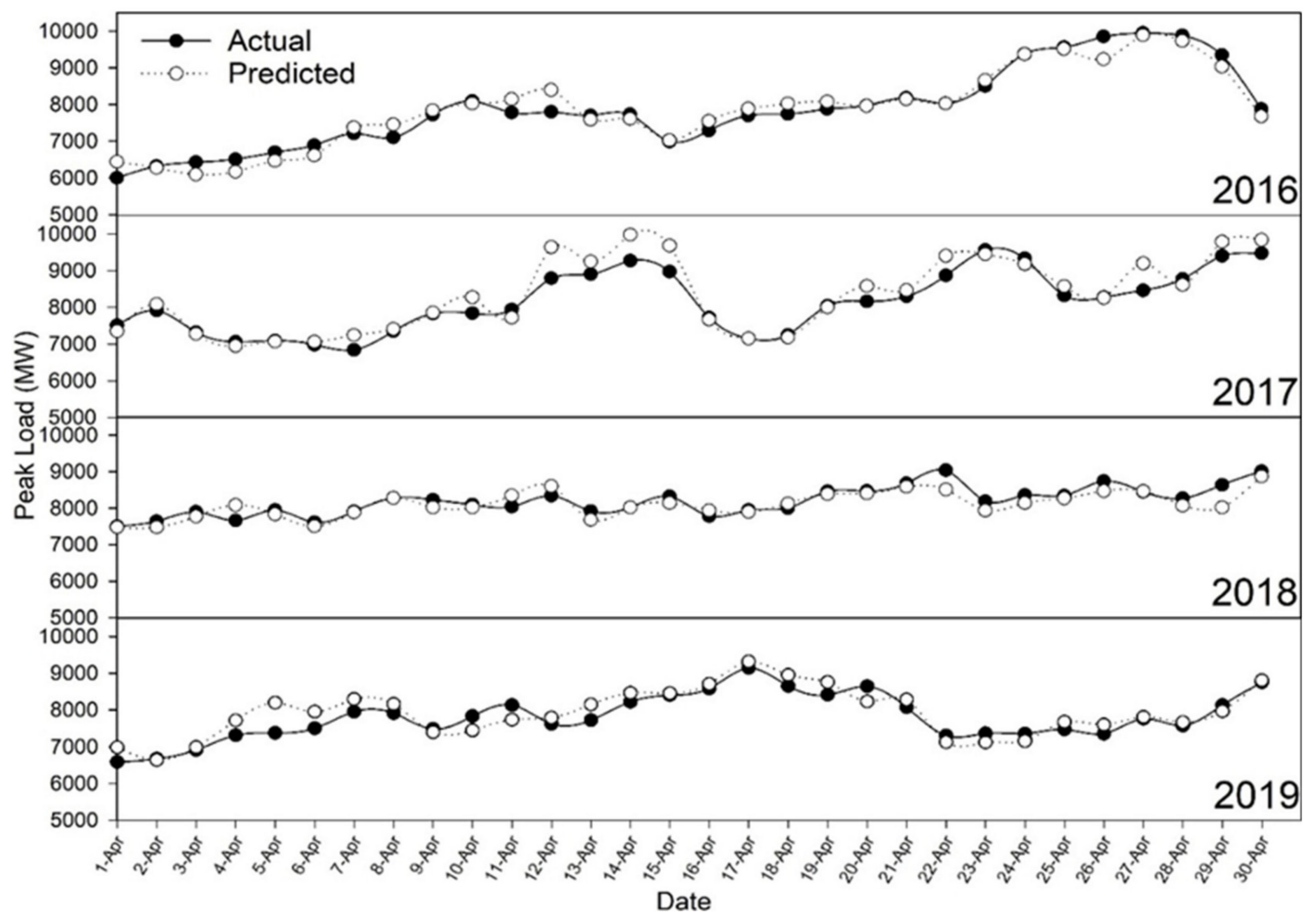

Figure 3. Daily peak load comparison obtained through regression analysis and actual data recorded over four consecutive years.

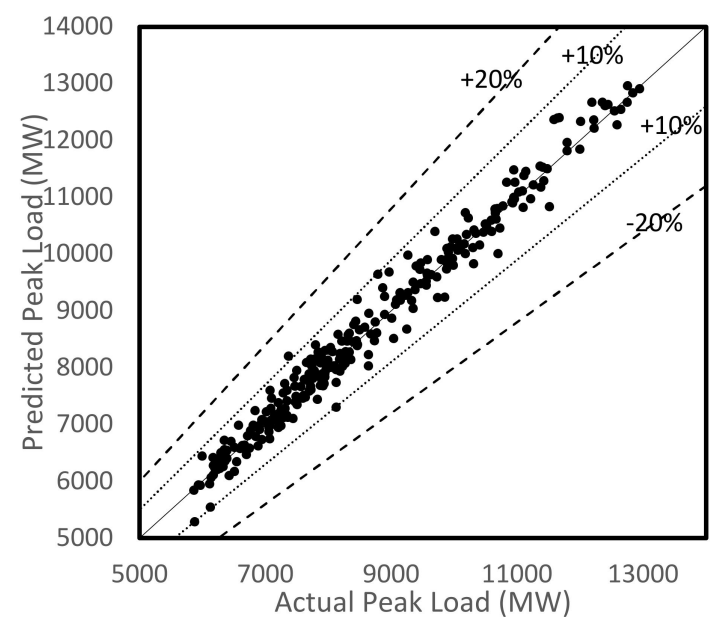

(a)

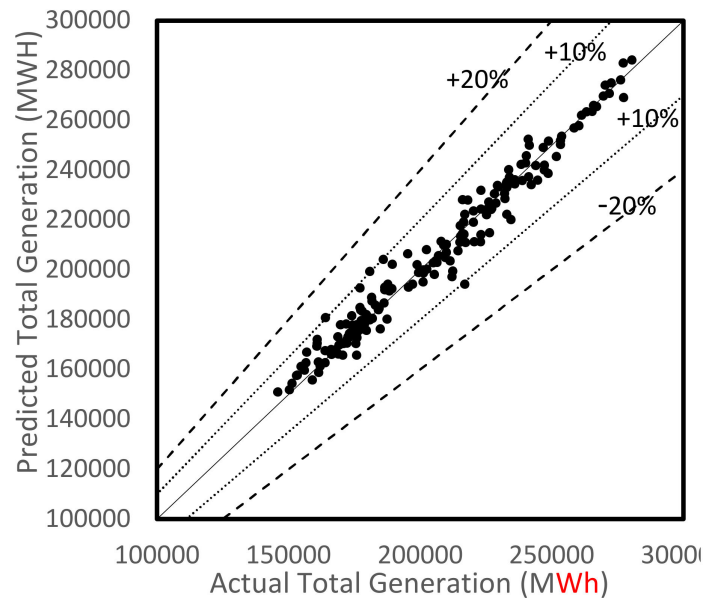

(b)

Figure 4. Comparison obtained through regression analysis and actual data recorded for March, April and May for 2017 to 2019, (a) peak load, and (b) total generation.

\subsection{Energy Demand}

Rising energy demand during the hot arid summer of Kuwait poses a potential threat to electricity security. Kuwait leads the world in energy consumption per capita. According to the latest statistical review of world energy, the average person in Kuwait consumed 17.9 MWh yearly in 2018, while in Italy, a country with the same GDP, the average person consumed only $4.8 \mathrm{MWh}$. This energy demand led to rapid increases in new power plant projects in Kuwait with a consequent increased environmental and economic impact. The average household in Kuwait consumes three times as much energy in the hot summer compared to winter, due mainly to the house cooling load [25]. However, 
in 2020 energy demand patterns have been directly affected by the COVID 19 pandemic through the introduction of regulations and precautions to mitigate the impact. These had a severe effect on energy demand as it was customary for a large percentage of the population to relocate in the summer to avoid the harsh conditions. With all travel halted there was a change to this usual practice.

The demand factor, the maximum peak load relative to the maximum load available, is an important energy industry security indicator. Figure 5 shows the demand factor for the Kuwait electric national grid for 18 consecutive years and it can be seen that since 2015 the demand factor had increased every year and is approaching the maximum value of unity, due to the rise in demand while the available power remains constant. The orange section of the column representing the demand factor, is the expected yearly average failure in the energy system as has occurred for the last ten years. In the summer of 2019, a total of five steam turbine power stations had 64 trips taking the units out of production for periods ranging from one hour to 4 months. A power station with a gas turbine unit had 77 trips that summer. Trip load shortages depend on the units and can vary between $10 \mathrm{MW}$ to 275 MW per unit. In 2006 and for some years subsequently, the demand exceeded the available electricity supply due to the severe summer hot weather and outdated equipment, and serious power cuts affected parts of Kuwait's residential areas [26].

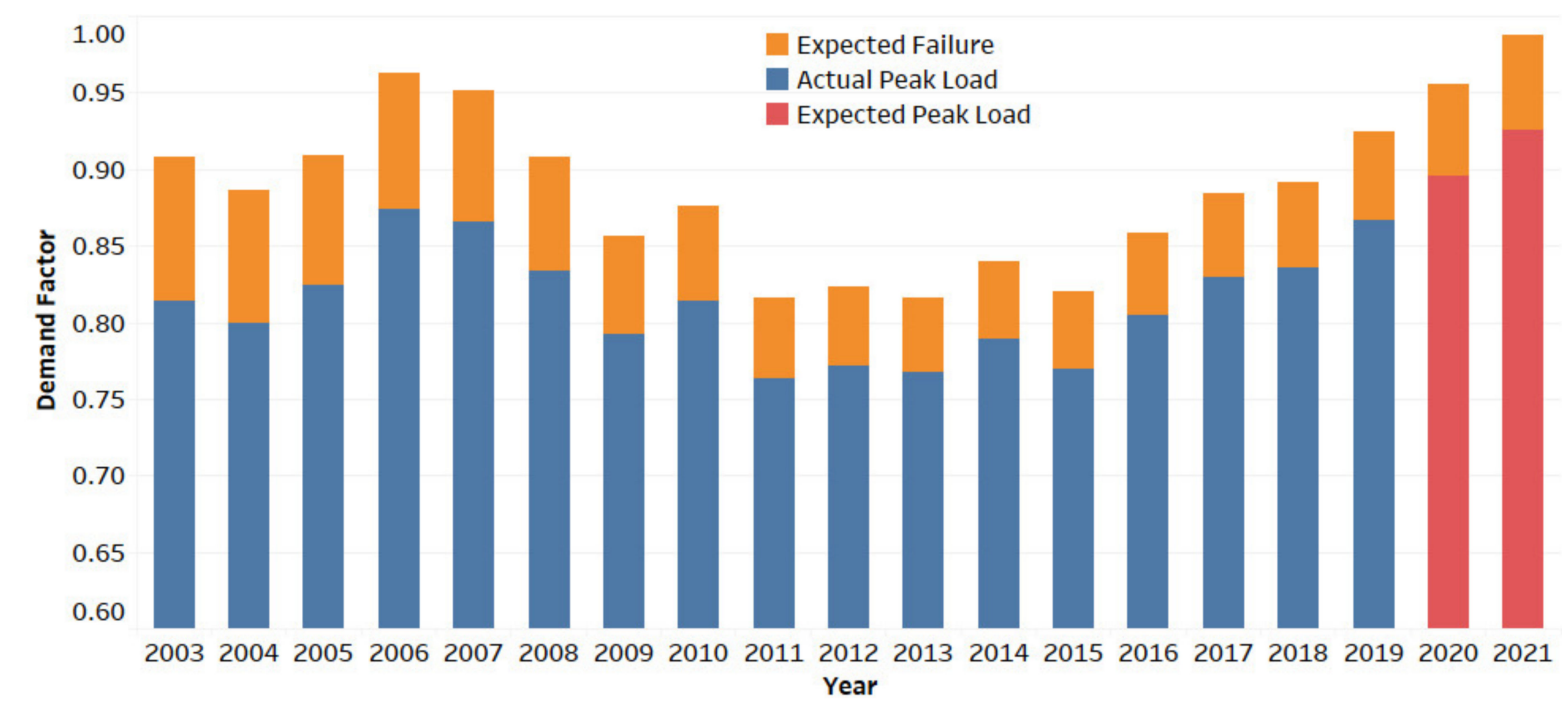

Figure 5. Demand factor in Kuwait electric national grid.

\subsection{Peak Load}

The peak load represents the maximum electrical demand on the national grid during a specific time. Usually, the power generation sector works to ensure the availability of power generating units with a capacity exceeding the expected peak load to provide a safe and secure electricity supply. The peak load should include not only the demand of the national grid network but also have sufficient capacity to allow routine maintenance and test programs which, typically, should be accomplished before the summer season starts. The national grid network is designed to be capable of withstanding a double contingency, so the power plants must operate at loads exceeding the expected load by $600 \mathrm{MW}$.

The peak load for the years 2019 and 2020 over the test period is shown in Figure 6. There are four lines, the blue stream refers to 2019 peak load and the orange stream represents 2020 peak load. The green stream illustrates the expected peak load for 2020 derived from the developed daily models. Finally, the yellow stream was extracted from another developed model designed to estimate the peak load during the curfew period. The first phase represents the normal condition, where the actual and estimated values are relatively close to each other and both are higher than the 2019 peak load due to expected growth in demand. At 6 March, the 2020 demand fell until reached a figure close to the previous year, that was because it was a Friday which is a holiday. For the period of stay at home 
(13-31, March) the trend is almost identical to the normal condition except for two days, when an increase occurred that could be attributed to media warnings and a partial government shut down.

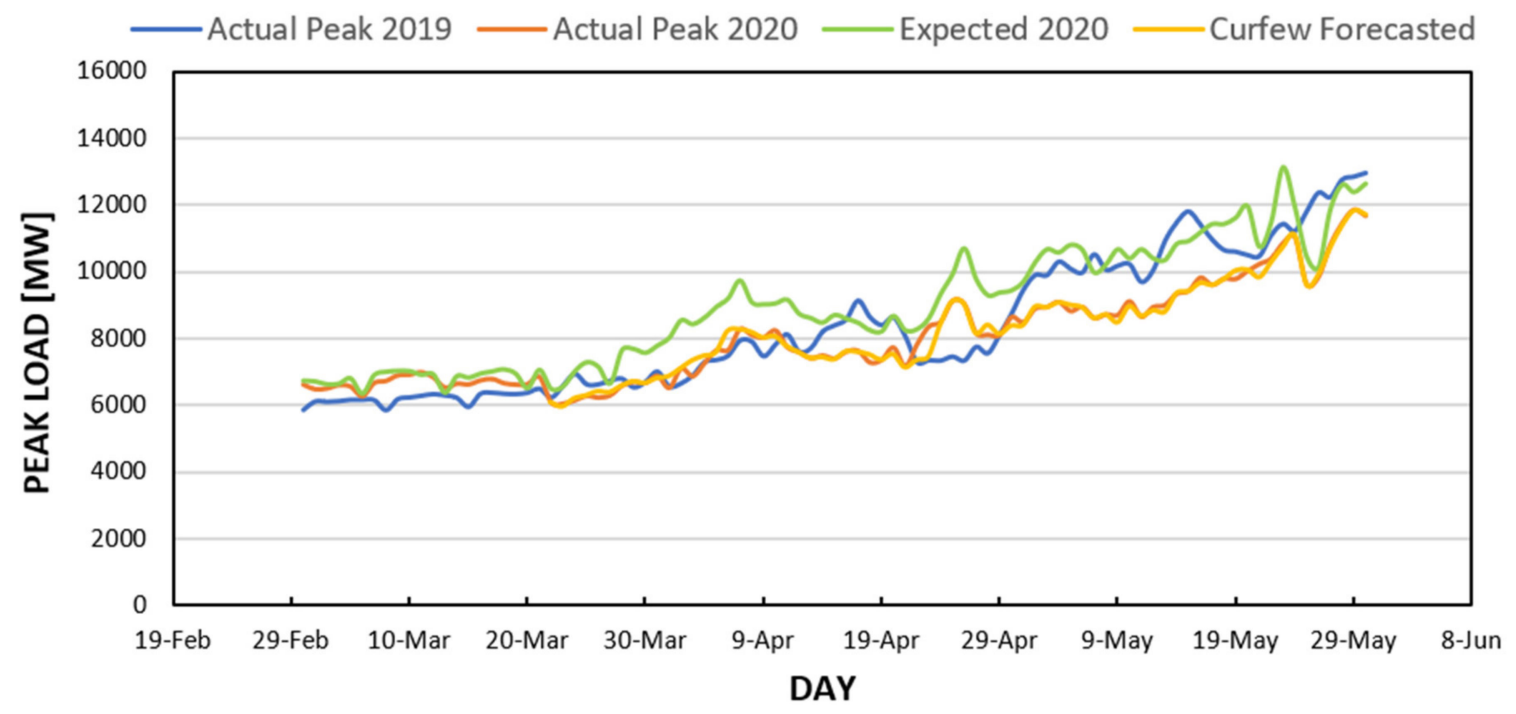

Figure 6. Daily peak load in MW over the test period.

Numerous outcomes can be extracted from the partial curfew load profile (22 March-10 May). First, the 2020 estimated peak load value was greater than the actual value, because the decrease in load due the industrial and commercial sectors closing was greater than the increase in residential consumption. Second, the partial curfew load is close to the 2019 peak load until the 13 April when the actual consumption for 2019 shows a sharp increase that lasts until 21 April. This was because of the high temperatures that occurred in 2019. Then, after 23 April, when Ramadan began, the trend for 2020 was upward, above that for 2019, when Ramadan began later, on 6 May. Normally, over the Ramadan period, the load on the electrical network increases by $4 \%$. For the full curfew period (11-30 May) both expected 2020 peak load and 2019 actual peak load exceeded the 2020 actual peak load. The differences are due mainly to the higher than average maximum temperature experienced in 2019. However, the highest differences between actual peak load and both baselines occurred in the last week of full curfew with values of 2510 MW and 2288 MW for 2019 and 2020, respectively.

A peak load comparison between the four control phases is presented in Figure 7. A 12-day sample is chosen for each situation (except phase 2 which represents the stay at home request which lasted for only 11 days) to demonstrate the effect of each control measure on peak load demand. A minimal change in peak load is shown. With time the difference increased as people started to follow the stay at home rule. There was a maximum drop in peak load after 7 days. After the government announced the coming partial curfew, behaviour changed and the peak load increased.

Both phases $3 \mathrm{a}$ and $3 \mathrm{~b}$ refer to the partial curfew situation, the difference between the two phase is the duration of the curfew. For phase $3 a$ the curfew period was $6 \mathrm{pm}$ to $4 \mathrm{am}(10 \mathrm{~h})$ while for phase $3 \mathrm{~b}$ the curfew period was $4 \mathrm{pm}$ to $8 \mathrm{am}(16 \mathrm{~h})$. The actual peak load reveals a maximum of $19 \%$ drop in demand after 11 days of imposed $10 \mathrm{~h}$ curfew. The red column in Figure 7 represents Fridays. Normally, the peak load drops on Friday due to the practice of all shop and services closing at noon. The lowest difference in both phases 2 and 3a occurs on Friday, which is to be expected due to the drop in peak load in normal conditions. The case is different for phase $3 \mathrm{~b}$ and 4 ; this is because of the commencement of the month of Ramadan. The average drop in peak load for the $10 \mathrm{~h}$ partial curfew was $12 \%$, whereas the average peak drop in load for the $16 \mathrm{~h}$ curfew was $13.3 \%$. Furthermore, the month of Ramadan started with the $16 \mathrm{~h}$ curfew, during Ramadan people stay up later at night and sleep longer in the day to cope with fasting during daylight hours. When the full curfew was 
introduced, the peak load continued to decline with an average drop of $13.6 \%$. Subsequently, a national 4 day holiday commenced; in such circumstances, the national peak load drops.

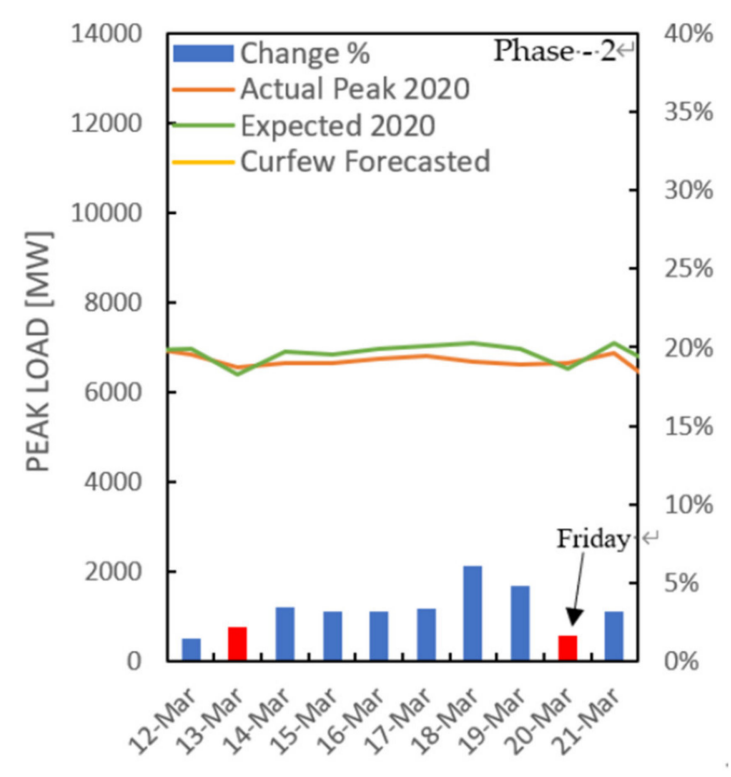

(a)

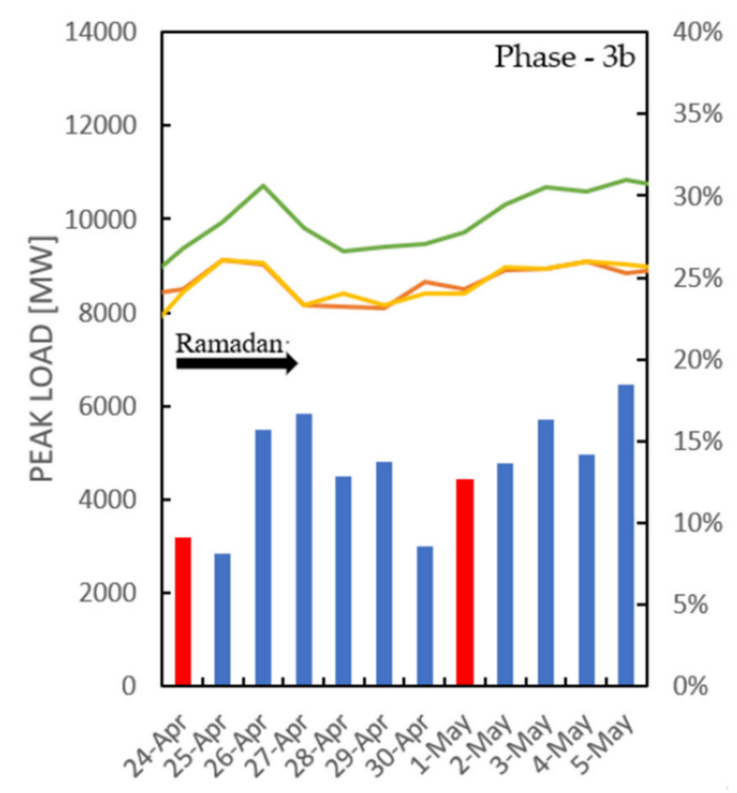

(c)

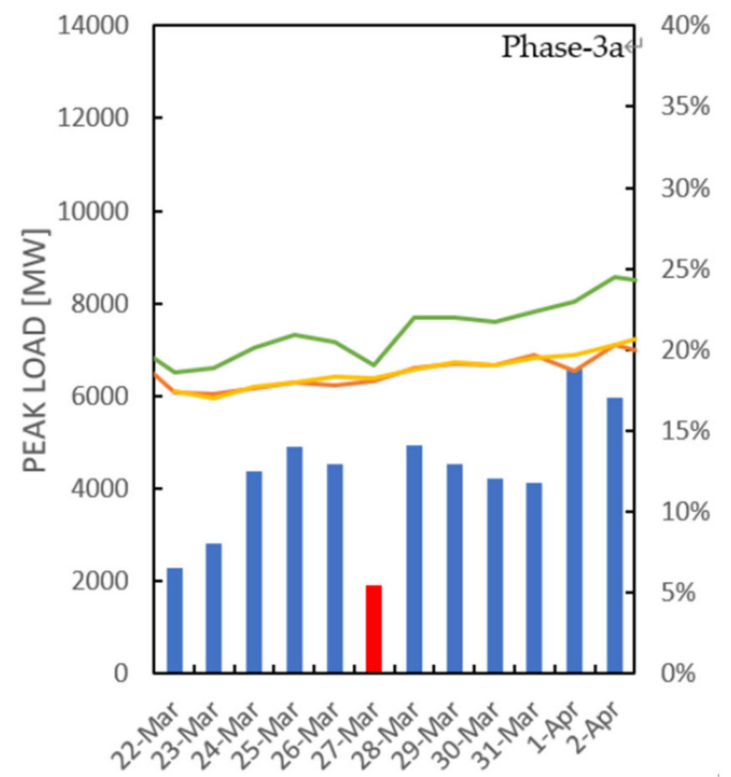

(b)

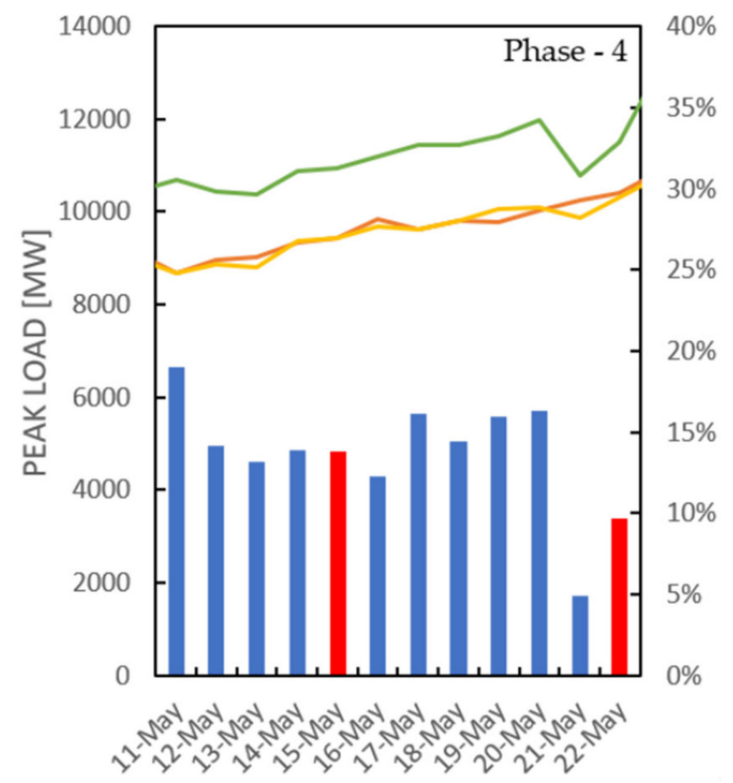

(d)

Figure 7. Change in peak load during four different phases of pandemic.

Previously there was a lack of information on energy consumption in the Kuwait residential sector because the Kuwait national grid recorded power consumption by municipal area. The lockdown gave a better understanding of Kuwait electricity consumption because, during lockdown, all the commercial sector was closed except for one supermarket in each residential area, the 44 main hospitals and approximately 90 local clinics. All industrial factories were closed with the exception of food supply and oil production which remained open. Schools, universities and government utility services were all closed. The oil company used $1100 \mathrm{MW}$ during the lockdown, and it is assumed the health 
services used 3\% of the peak load. Over $80 \%$ of Kuwait's power consumption during the lockdown was residential.

\subsection{Total Power Generation}

Peak load forecasting which is for a relatively short period not exceeding hours is necessary for electrical grid stability. In contrast, evaluating total power generation is important to determine the amount of fuel requirement and estimate the revenue and profitability of energy systems. Figure 8 illustrates the total power generation in MWh over the test period. For the first two phases, the actual power generation was almost identical to the estimated value for 2020 and both registered higher values than in 2019. In the partial curfew phase, the values forecast were higher over the whole period, but the actual values for 2020 fluctuated reasonably close to those for 2019 until the end of April when the actual 2020 values were significantly lower than those for 2019. The fluctuations are attributed to temperature difference since the higher temperature recorded in 2019 meant more power generation. During the full curfew phase, the differences became clearer, the highest values are for 2020 estimated power generation followed by the 2019 actual values and finally the 2020 actual values. The reason behind the substantial reduction in 2020 power generation is the shutdown of more sectors of the economy compared to the previous phases. The stay at home phase recorded a $2.2 \%$ reduction in power generation, while the partial curfew phase shows a $13.7 \%$ reduction in power consumption compared to that expected for 2020. The highest reduction in power consumption occurred in the full lockdown phase with $17.6 \%$ drop compared to the 2020 prediction.

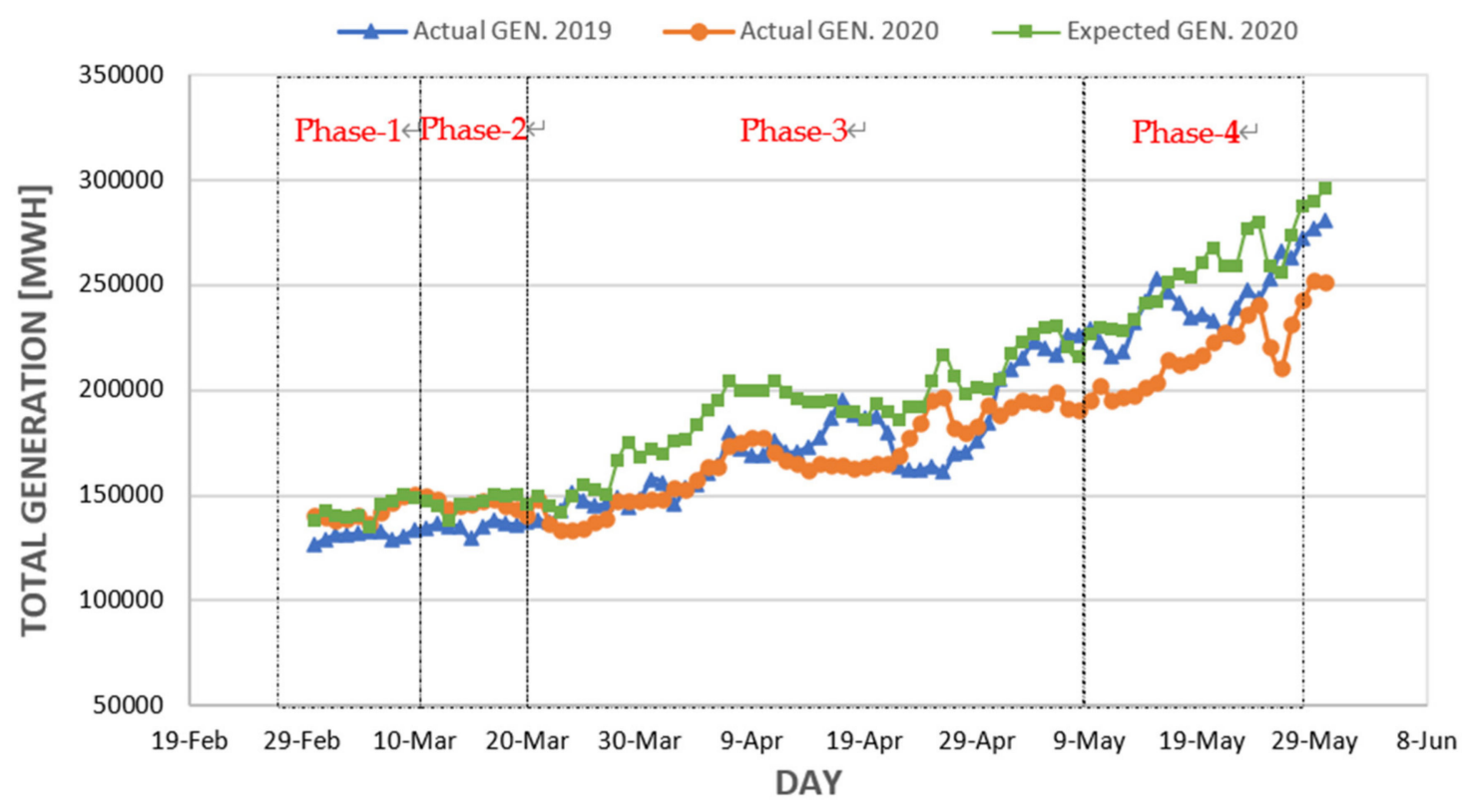

Figure 8. Total power generation in MWh over the test period 1st March-30 May.

\subsection{Economic Assessment}

Economic assessment of the impact of the COVID-19 pandemic on Kuwait electrical network will enrich current research by showing the financial consequences of operational and technical aspects of the national grid. Power plants in Kuwait predominantly utilize non-renewable resources, such as natural gas, gas oil, crude oil and heavy fuel oil. The fuel prices of each type are different and fluctuate based on demand in the global markets. Gas oil is the most expensive, while local natural gas is the cheapest, and the price of the other two fuel types lie between them. Natural gas was selected to evaluate the financial saving which means the result will show the minimum saving, the saving will be higher in the case of using another fuel. Figure 9 shows the monthly saving in US\$ million 
over the pandemic period. As mentioned above, two baselines were selected for the evaluation, first the actual reading for last year (2019) and the second the values forecast for 2020 based on normal circumstances. Over the test period, the amount of energy consumed each month in 2020 was less than that consumed in 2019, despite expected annual growth. The amount of saving increased as the partial curfew was extended to a full curfew, which is as expected. In the month of April, the saving was reduced compared to March 2019 because of a lower difference in average temperature. The total value of energy savings for the entire test period were about US $\$ 31.58$ million and US $\$ 71.95$ million for 2019 and 2020, respectively.
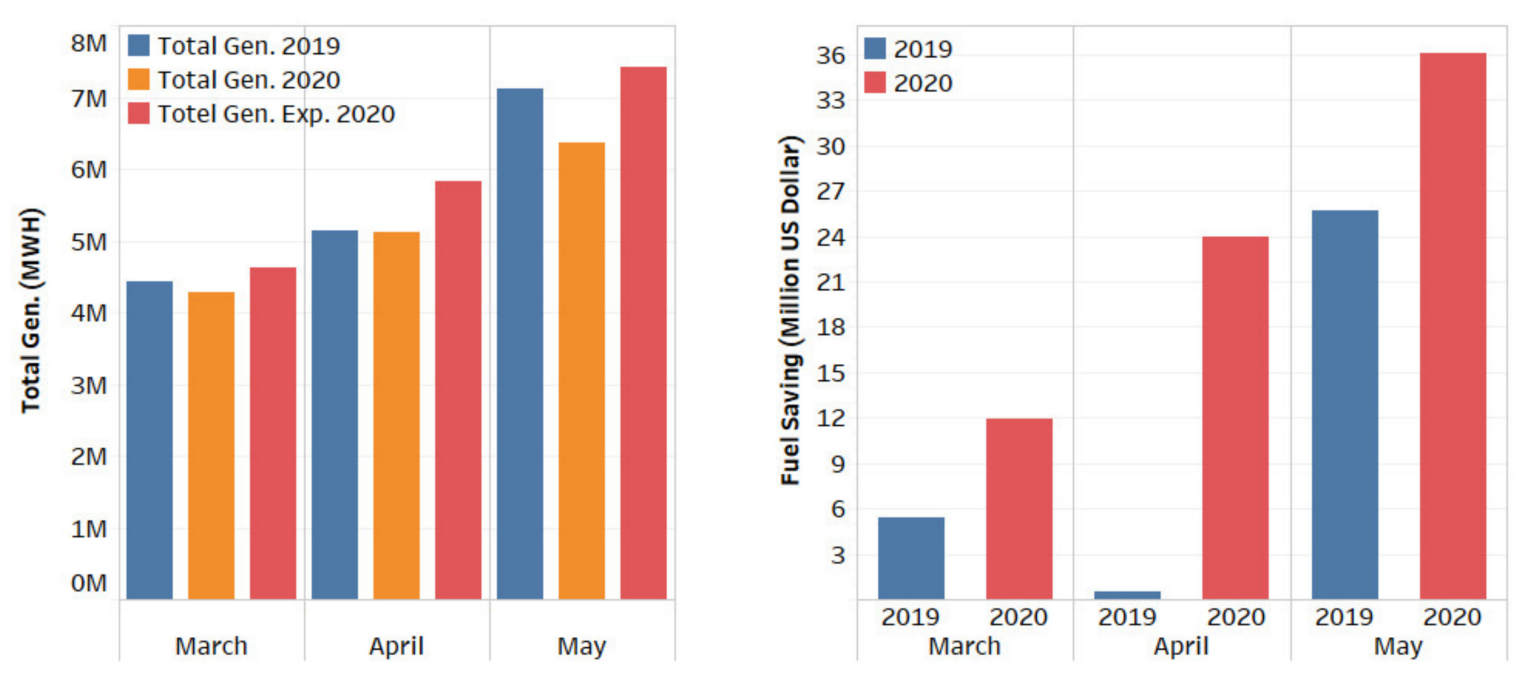

Figure 9. Monthly fuel-saving in US\$ million over the pandemic period compared to actual expenditure in 2019 and projected expenditure for 2020.

\subsection{Environmental Impact}

Non-renewable power plants burnings fossil fuels are considered a reliable source of electricity generation, but during the production process release a considerable amount of pollutant and greenhouse emissions. Figure 10 shows the decrease in $\mathrm{CO}_{2}$ emissions in kilo-tonnes emitted from the power plants into the environment over the given test periods. Generally, $\mathrm{CO}_{2}$ emission is strongly related to the energy-conversion efficiency of the power plants as well as the air-fuel ratio during the combustion process. Low heat rate and stoichiometric air-fuel ratio lead to high levels of emission with low $\mathrm{CO}_{2}$ intensity. May 2020 recorded the highest reduction of $\mathrm{CO}_{2}$ emissions compared to the predicted values due to the full curfew, while March has the lowest. The differences between ambient temperatures in April explain the reduction compared to actual emissions in 2019. The reductions of $\mathrm{NO}_{\mathrm{x}}$ and $\mathrm{CO}$ emissions in tonnes are also shown in Figure 10. The level of emissions shows the same trend as $\mathrm{CO}_{2}$ over the test period because all three are associated with burned fuel as well as power generation. The released quantities of $\mathrm{NO}_{x}$ emissions are higher than $\mathrm{CO}$ due to excess air introduced into the combustors to avoid incomplete combustion. The total emissions are around 119, 0.335 and 3.39 kilo-tonnes for $\mathrm{CO}_{2}, \mathrm{CO}$ and $\mathrm{NO}_{x}$, respectively, based on 2020 forecasting. These results were extracted from the environmental impact model and showed good agreement with the outcomes of a recent study implemented by Kuwait electric power systems [27]. 


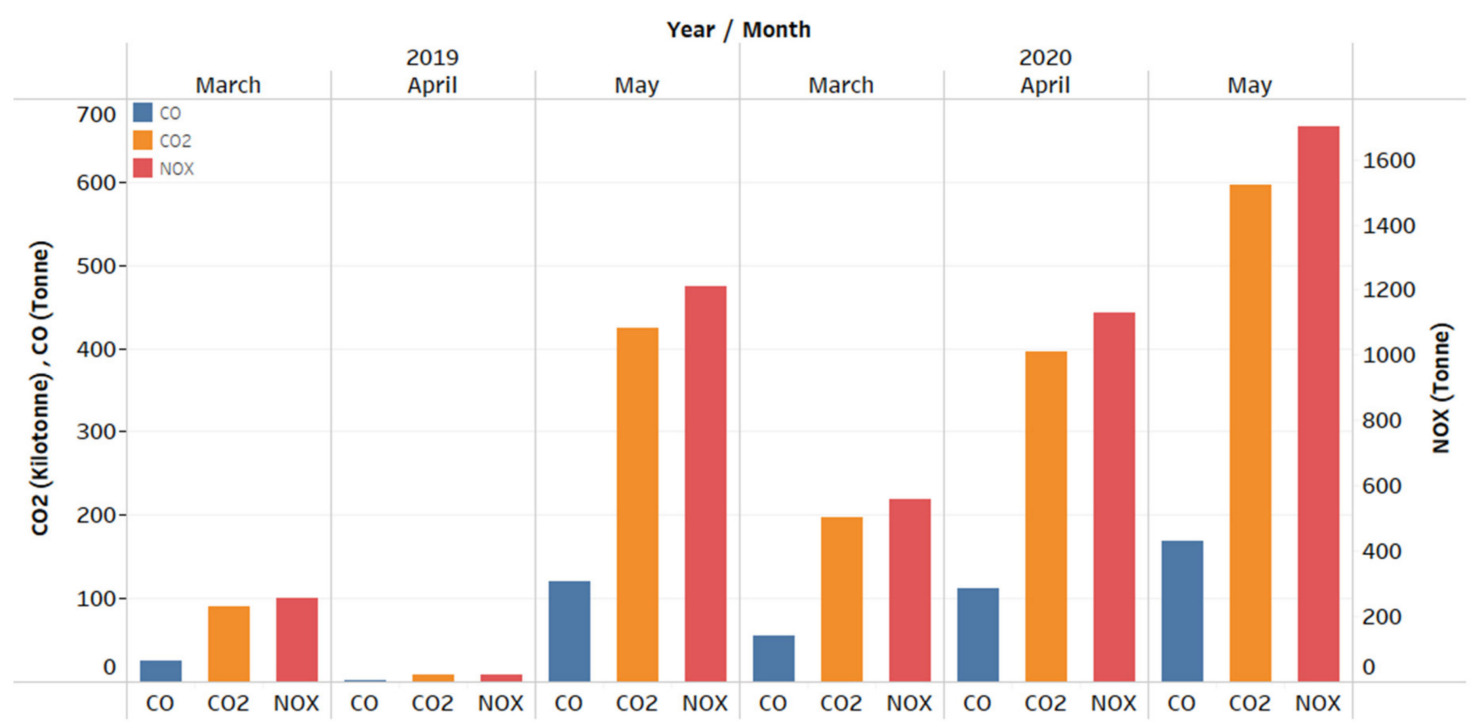

Figure 10. Decrease in emissions of $\mathrm{CO}_{2}, \mathrm{NO}_{x}$ and $\mathrm{CO}$ pollutants over the period of partial and full curfews.

\section{Conclusions}

In light of the above information, the present study's outcomes show high compatibility with published reports by the International Energy Agency and other concerned agencies regarding a decrease in electricity demand, which takes place at different levels of reduction. The electrical grid of the state of Kuwait was selected as a case study, and the results are applicable in other countries, with allowances in the general trend made on the basis of the electrical grid's size, its configuration and the local economy. The current study lays the groundwork for future research that addresses the consequences of pandemics on the energy sector.

This paper sheds light on the impact of measures to protect the population of Kuwait from COVID 19 on the Kuwait electrical national grid from technical, economic and environmental perspectives. A genetic algorithm has been used to evaluate the peak load and total energy consumption during three consecutive months, which constitute four different patterns of grid performance. Economic and environmental models have been developed to assess the fuel-saved, and thereby the reduction in pollutant emissions and greenhouse gases released to the atmosphere.

The main findings of the study are:

- The preventive actions against COVID-19 led to a significant, measured reduction in total power generation compared to the growth estimated for 2020, and to the actual consumption in 2019. Peak loads during 2019 sometimes registered readings higher than the actual peak load in 2020 due to higher ambient temperatures in 2019.

- The energy consumption reduction in governmental, industrial and commercial sectors was greater than the increase in residential consumption and that was reflected in peak load reduction.

- The average drop in peak load for the partial curfew ranged between $12 \%$ to $13.3 \%$ based on the duration of the curfew while for full lockdown the average decrease was $13.6 \%$.

- The stay at home phase (13-21 March) recorded a 2.2\% reduction in power generation while the partial curfew (22 March-10 May) and full lockdown (11-30 May) phases showed 13.7\% and $17.6 \%$ reductions respectively relative to the 2020 forecasted values.

- The total amount of fuel-saving for the whole tested period was about US\$31.58 million and US\$71.95 million, based on the actual record of 2019 and estimated growth for 2020, respectively.

- May 2020 was more environmentally friendly with lowest $\mathrm{CO}_{2}$, NOx and $\mathrm{CO}$ emissions compared to all the other tested phases due to full lockdown. 
- The energy consumption during the lockdown was predominantly from the residential sector and showed that the residential sector represents about $62 \%$ of energy consumption in Kuwait. This represents one of the highest domestic consumptions in the world. Thus, to substantially reduce energy consumption in Kuwait requires measures by the government to lower household energy consumption, and the Ministry of Electricity and Water is advised to implement new and more rigorous policies and regulations to ensure less energy is consumed.

- This paper was restricted to the state of Kuwait under specific circumstances, which means there were numerous limitations imposed by data availability, governance strategy and the scope of the work. For example, the electrical power generating units considered were limited to gas turbines fueled by natural gas, but other systems use other generators, and other fuels, and these alternatives need to be considered. This is important when assessing likely environmental impact. Furthermore, the use of renewable resources feeding the existing electrical network configuration should be investigated. The state of Kuwait chooses to subsidize electricity so the price paid by the consumer is only a small fraction of production costs, but this will vary from country to country and needs to be addressed in any general model as profitability is an essential factor in electricity production. These and other considerations could serve as good bases on which to further extend this study.

Author Contributions: Conceptualization, H.M.A. and A.A. (Abdulrahman Almutairi); data curation, F.A.; Investigation, H.M.A., A.A. (Abdulrahman Almutairi), A.A. (Abdulrahman Alenezi) and F.A.; validation, H.M.A., A.A. (Abdulrahman Almutairi); writing-original draft, H.M.A., A.A. (Abdulrahman Almutairi) and A.A. (Abdulrahman Alenezi). All authors have read and agreed to the published version of the manuscript.

Funding: This research received no external funding.

Acknowledgments: The authors wish to express their sincere thanks to the Ministry of Electricity and Water in the state of Kuwait for its valuable support and assistance to the current work.

Conflicts of Interest: The authors declare no conflict of interest.

\section{References}

1. Ozili, P.K.; Arun, T. Spillover of COVID-19: Impact on the Global Economy. SSRN Electron. J. 2020. [CrossRef]

2. Sohrabi, C.; Alsafi, Z.; O’Neill, N.; Khan, M.; Kerwan, A.; Al-Jabir, A.; Iosifidis, C.; Agha, R. World Health Organization declares global emergency: A review of the 2019 novel coronavirus (COVID-19). Int. J. Surg. 2020, 76, 71-76. [CrossRef] [PubMed]

3. IATA Potential for Revenue Losses of $\$ 113 \mathrm{bn}$ Due to COVID-19 “Crisis". Available online: https://www.iata. org/en/pressroom/pr/2020-03-05-01/ (accessed on 5 March 2020).

4. Turk, D.; Kamiya, G. Global Energy Review 2020,The Impacts of the COVID-19 Crisis on Global Energy Demand and CO2 Emissions; IEA: Paris, France, 11 June 2020; Available online: https://www.iea.org/articles/the-impact-ofthe-covid-19-crisis-on-clean-energy-progress (accessed on 5 March 2020).

5. Debnath, K.B.; Mourshed, M. Forecasting methods in energy planning models. Renew. Sustain. Energy Rev. 2018, 88, 297-325. [CrossRef]

6. Leme, J.V.; Casaca, W.; Colnago, M.; Dias, M.A. Towards assessing the electricity demand in Brazil: Data-driven analysis and ensemble learning models. Energies 2020, 13, 1407. [CrossRef]

7. Sigauke, C.; Chikobvu, D. Prediction of daily peak electricity demand in South Africa using volatility forecasting models. Energy Econ. 2011, 33, 882-888. [CrossRef]

8. Elias Barrón, I.; De, J.; Rubio, J.d.J.; Martinez, D.; Vargas, T.; Garcia, V.; Mújica-Vargas, D.; Meda Campaña, J.; Pacheco, J.; Gutierrez, G.; et al. Genetic Algorithm with Radial Basis Mapping Network for the Electricity Consumption Modeling. Appl. Sci. 2020, 10, 4239. [CrossRef]

9. Arnaout, J.-P. Forecasting Kuwait's Electricity Consumption Using Genetic Algorithms. J. Energy Dev. 2016, 42, 223-237.

10. Wang, Q.; Su, M. A preliminary assessment of the impact of COVID-19 on environment-A case study of China. Sci. Total Environ. 2020, 728, 138915. [CrossRef] 
11. Kanniah, K.D.; Kamarul Zaman, N.A.F.; Kaskaoutis, D.G.; Latif, M.T. COVID-19's impact on the atmospheric environment in the Southeast Asia region. Sci. Total Environ. 2020, 736, 139658. [CrossRef]

12. Filonchyk, M.; Hurynovich, V.; Yan, H.; Gusev, A.; Shpilevskaya, N. Impact Assessment of COVID-19 on Variations of SO2, NO2, CO and AOD over East China. Aerosol Air Qual. Res. 2020, 20, 1530-1540. [CrossRef]

13. Rugani, B.; Caro, D. Impact of COVID-19 outbreak measures of lockdown on the Italian Carbon Footprint. Sci. Total Environ. 2020, 737, 139806. [CrossRef] [PubMed]

14. Abu-Rayash, A.; Dincer, I. Analysis of the Electricity Demand Trends amidst the COVID-19 Coronavirus Pandemic. Energy Res. Soc. Sci. 2020, 101682. [CrossRef]

15. Gillingham, K.T.; Knittel, C.R.; Li, J.; Ovaere, M.; Reguant, M. The Short-run and Long-run Effects of Covid-19 on Energy and the Environment. Joule 2020, 4, 1337-1341. [CrossRef]

16. Aruga, K.; Islam, M.M.; Jannat, A. Effects of COVID-19 on Indian energy consumption. Sustainability 2020, 12, 5616. [CrossRef]

17. Montgomery, D.; Runger, G. Applied Statistics and Probability for Engineers; John Wiley \& Sons: Hoboken, NJ, USA, 2014; ISBN 9781118744123.

18. Thomas Ng, S.; Skitmore, M.; Wong, K.F. Using genetic algorithms and linear regression analysis for private housing demand forecast. Build. Environ. 2008, 43, 1171-1184. [CrossRef]

19. Santos, R.S.; Matias, J.C.O.; Abreu, A.; Reis, F. Evolutionary algorithms on reducing energy consumption in buildings: An approach to provide smart and efficiency choices, considering the rebound effect. Comput. Ind. Eng. 2018, 126, 729-755. [CrossRef]

20. Amjadi, M.H.; Nezamabadi-pour, H.; Farsangi, M.M. Estimation of electricity demand of Iran using two heuristic algorithms. Energy Convers. Manag. 2010, 51, 493-497. [CrossRef]

21. Goldberg, D.E. Genetic Algorithms in Search, Optimization and Machine Learning, 1st ed.; Addison-Wesley Longman Publishing Co., Inc.: Boston, MA, USA, 1989; ISBN 0201157675.

22. Ministry of Electricity and Water. Electricity Statistics Year Book; Ministry of Electricity and Water: Kuwait City, Kuwait, 2020.

23. Rizk, N.K.; Mongia, H.C. Semianalytical Correlations for NOx, CO, and UHC Emissions. J. Eng. Gas Turbines Power-Trans. ASME 1993, 115, 612-619. [CrossRef]

24. Al-Dousari, A.; Al-Awadhi, J. Dust fallout in northern Kuwait, major sources and characteristics. Kuwait J. Sci. Eng. 2012, 39, 171-187.

25. Ameer, B.; Krarti, M. Impact of subsidization on high energy performance designs for Kuwaiti residential buildings. Energy Build. 2016, 116, 249-262. [CrossRef]

26. Alotaibi, S. Energy consumption in Kuwait: Prospects and future approaches. Energy Policy 2011, 39, 637-643. [CrossRef]

27. Alhajeri, N.S.; Al-Fadhli, F.M.; Aly, A.Z. Unit-based emissions inventory for electric power systems in Kuwait: Current status and future predictions. Sustainability 2019, 11, 5758. [CrossRef] 